\title{
ECTOPIC KIDNEY WITH ANTERIOR MALROTATION ASSOCIATED WITH CRYPTORCHIDISM.
}

\section{Taneja Vipul1, Sodhi Kirandep², Goud Raghavendra33, Dr.Rasmeen Kaur4}

'Assistant Professor, Department of Pediatrics, Maharishi Markandeshwar Institute of Medical Sciences and Research, Ambala, Haryana, India.

2 Professor, Department of Pediatrics, Maharishi Markandeshwar Institute of Medical Sciences and Research, Ambala, Haryana, India. ${ }^{3}$ Resident, Department of Pediatrics, Maharishi Markandeshwar Institute of Medical Sciences and Research, Ambala, Haryana, India. ${ }^{4}$ Kaur Rasmeen, Senior Resident, Department of Anaesthesiology, Maharishi Markandeshwar Institute of Medical Sciences and Research, Ambala, Haryana, India.

\section{Email id : drvipultaneja@gmail.com}
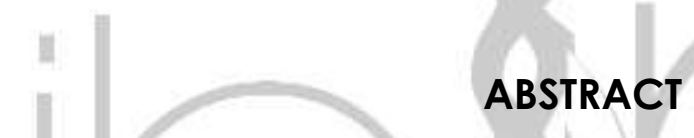

Malrotation of kidney with ectopia is uncommon. As such This condition is generally asymptomatic and usually diagnosed as incidental finding. We came across this case in association with left sided cryptorchidism. Child presented with increased urinary frequency.

Keywords: undescended testis, ectopic kidney 


\section{CASE REPORT}

A 14-year-old adolescent male came to OPD with single complaint of frequent urination for a duration of 3 months, child visits rest room several times during day and after night hours. There was no history of bed wetting now or during early childhood. There was no associated history of burning micturition, fever, radiating pain in abdomen. No high colored urine, no other bowel symptoms. Child was a k/c/o cryptorchidism at birth but was not further investigated. On ultrasound Testis in superficial inguinal ring. Abdominal ultrasound showed left kidney was visualized in left lumbar fossa, mal-rotated with hilum facing anteriorly. The echotexture is normal and no calculus seen. Renal function test was normal. Perinatal history had no significant clues. laproscopic assisted leftorchidopexy was planned 


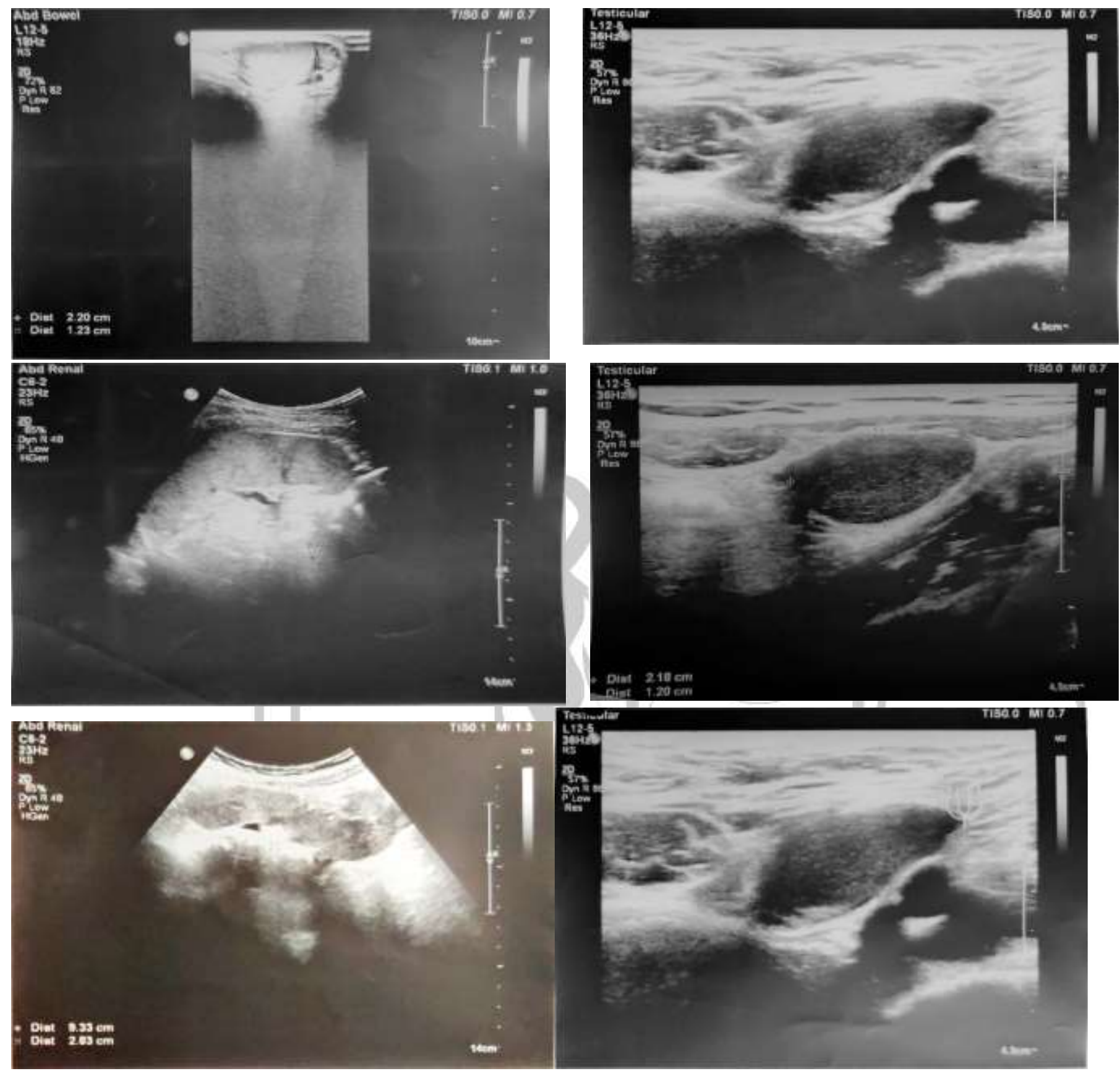

2021 July Edition | www.jbino.com | Innovative Association inting 


\section{Discussion:}

Incidence of ectopic kidney is not uncommon, 1:12,000 clinical and 1:900 postmortem cases. indicating clinically benign significance of this usually asymptomatic aberration'. But with combined occurrence with cryptorchidism would be quiet rare.Ectopic kidneys are due to developmental anomalies. Kidneys normally start to develop in the

pelvis and migrate to their normal anatomical position in the upper abdomen. The ascent of the kidneys precedes the descent of the gonads into the pelvis. Caudal growth in the embryo appears to assist in

migration of the kidneys out of the pelvis into their eventual retroperitoneal location in the renal fossa. They attain their adult position by the 9th gestational Week ${ }^{2}$. Ectopic kidneys may be pelvic, iliac or abdominal, anywhere along the path of their usual ascent or contralateral, referred to as "crossed", with a slight predominance on the left side and in males $^{3}$. Ectopic kidney is often associated with other abnormalities such as agenesis of the opposite kidney, vascular malformation and genital anomalies.

Cryptorchidism is the most common congenital genitourinary condition in male infants. There are believed to be 2 peaks for diagnosis of cryptorchidism. At birth and between 5 and 7 years of age. While most cases are diagnosed at birth, the increased detection rate at 5 to 7 years is thought to be secondary to linear body growth. The fact that descent is not complete until the third trimester in most boys explains the higher incidence of cryptorchidism seen in preterm boys. Second, the influence of androgens and hormones on testicular descent, especially in the transinguinal phase, is one possible explanation for the increased rate of spontaneous testicular descent in the first 3 months after birth. Around 60 to 90 days after birth, the neonate normally undergoes what is often referred to as a "mini-puberty," when there is a surge of gonadotropins ${ }^{4}$ Presentation is mostly asymptomatic, but may have urgency, calculus, UTI.

\section{REFERENCES}

1.Fetal pelvic kidney: a challenge in prenatal diagnosisMeizner I, Yitzhak $M$, Levi A, Barki $Y$, Barnhard $Y$, Glezerman $M$ Ultrasound Obstet Gynecol. 1995 Jun; 5(6):391-3.

2. Walsh P, Gittes R, Perimutter A. Cambell's Urology. edition Philadelphia: WB Saunders, 1986:1674-5

3. GE Healthcare Renal ectopia. Available from www.medcyclopaedia.com. 
4. Pediatric Urology of Primary Textbook of Clinical Nephrology.Oxford: care,American Academy of Pediatrics; pg- $\quad$ Oxford University Press, Inc, 2005:1402-12. 73.

5. Rascher W, Rosch WH. Congenital abnormalities of theurinary tract. Oxford

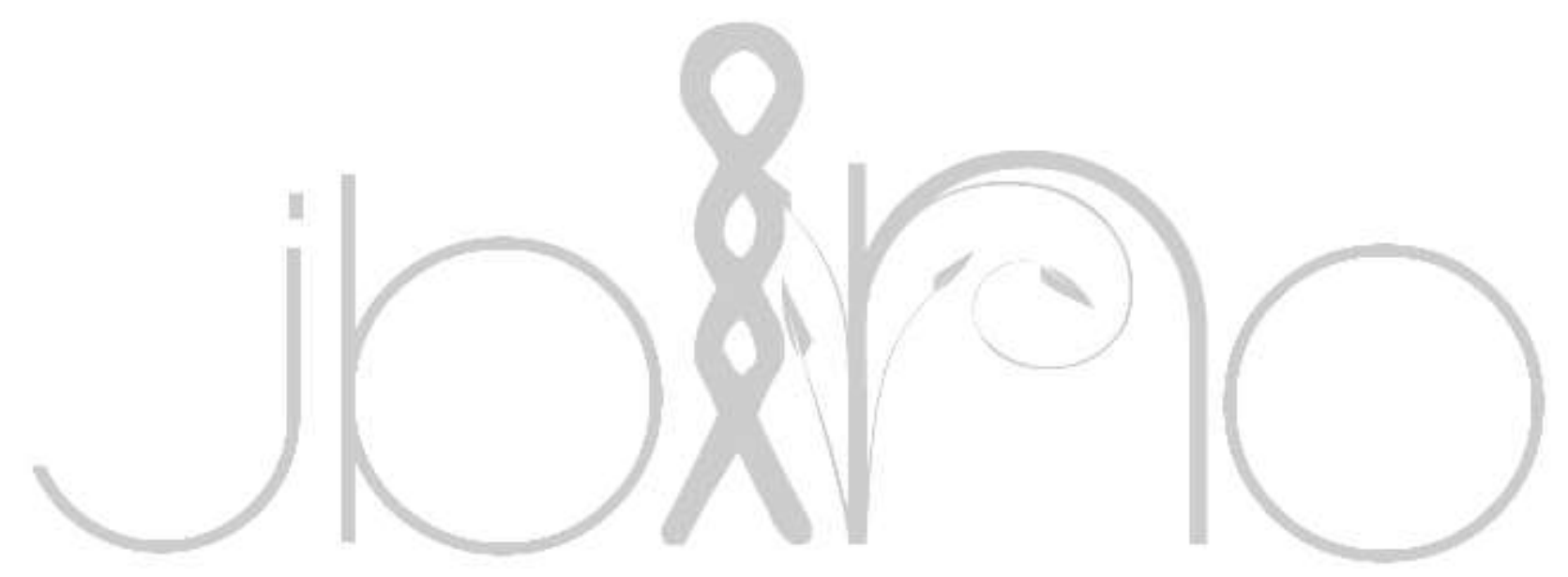

